


\title{
MITTEILUNGEN
}

der

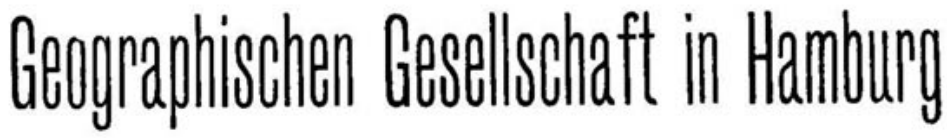

\section{Band XXIX}

\author{
Im Auftrage des Vorstandes herausgegeben \\ von \\ Dr. L. Friederichsen \\ Erstem Schriftführer
}

Mit einer zweiblättrigen topographischen Karte im Maßstabe von 1:300000 und 47 Abbildungen auf 27 Tafeln

Alle Rechte vorbehalten

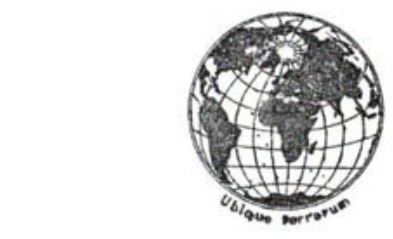

HAMBURG

L. Friederichsen \& Co.

(Inhaber: Dr. L. u. R. Friederichsen)

Land- und Seekartenhandlung

geographischer und nautischer Verlag

1915 


\title{
Das \\ abflußlose Rumpfschollenland im
}

\section{nordöstlichen Deutsch-Ostafrika}

\author{
Bericht über eine \\ im Auftrag der Hamburgischen Geographischen Gesellschaft \\ in den Jahren 1911/12 ausgeführte Forschungsreise \\ von \\ Dr. Erich Obst \\ Privatdozenten der Geographie an der Universität Marburg \\ Teil I \\ Aufgaben, Vorbereitung und Verlauf der Reise. - Ergeb- \\ nisse der topographischen Arbeiten und der Sammlungen \\ Mit Beiträgen von \\ P. Sprigade, M. Moisel, A. Wedemeyer, R. Herzenberg, W. Heering, \\ L. Diels, O. Steinhaus, F. Werner, M. Leschke, M. v. Brunn, \\ K. Kraepelin, A. Ried, O. Reche
}

Mit einer zweiblättrigen topographischen Karte im Maßstabe von $1: 300000$ und 47 Abbildungen auf 27 Tafeln

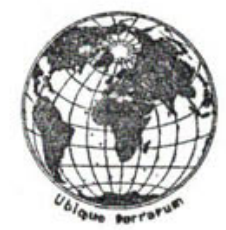

HAMBURG

L. Friederichsen \& Co.

(Inhaber: Dr. L. u. R. Friederichsen)

Land- und Seekartenhandlung

geographischer und nautischer Verlag

1915 
Alle Rechte vorbehalten. 